\title{
Investigation on Workability Of M20 Grade Concrete With Partial Replacement Of Crumb Rubber And M Sand For Fine Aggregates And Flyash For Cement
}

\author{
P.Santhi $\mathrm{Raj}^{1}$, G.V.V.Satyanarayana ${ }^{2}$, and M. Sriharshavarma ${ }^{3}$ \\ ${ }^{1}$ Department of civil engineering, Gokaraju Rangaraju Institute of Engineering \& Technology, Hyderabad-5000902,India. \\ ${ }^{2}$ Department of civil engineering, Gokaraju Rangaraju Institute of Engineering \& Technology, Hyderabad-5000902,India. \\ ${ }^{3}$ Department of civil engineering, Gokaraju Rangaraju Institute of Engineering \& Technology, Hyderabad-5000902,India.
}

\begin{abstract}
Concrete has a key role in construction. Study focus on workability of the concrete, Fine Aggregate is partially filled with crumb rubber and M sand, a part of cement is replaced with fly ash. In this investigation the crumb rubber is utilised in place of fine aggregate. The scrap tyre treatment is currently a serious issue against environmental pollution. India stud in forth position in the entire world for rubber tyre market world after china, Europe and the US. Fly ash and M sand is an industrial waste which is included in the concrete. In this investigation workability of concrete is conducted on M20 grade concrete by replacing river side sand with the $\mathrm{M}$ sand and crumb rubber at percentage of replacements 0 to $20 \%$ at an regular interval of $5 \%$ and Compare the results obtained by the modified concrete with the normal concrete.
\end{abstract}

\section{INTRODUCTION}

In construction industry, concrete is basic designing constituent. it is a mix of cement, fine aggregate, coarse aggregate and water in order to improve workability of the concrete along with supplementary materials like fly ash, manufactured sand is used in this investigation. With the development of the modern society aftermath of industrial revolution, the mobility with in automobile sector got momentum. Tyre rubber waste represents major environmental of increasing significance. The extent of present exploration is the study of rubber waste created from the left over tyres and probability of utilising waste tyre rubber as the partial substitution of the fine aggregate in order to generate rubberized concrete, and 3days compression strength of the concrete,[1] The coarse aggregate is replaced with chipped tyres with $5 \%, 7.5 \%$ and $10 \%$. and likewise the same replacement ratios of powder tyre Crump is called as Crump Rubber(CR) with cement. the reduction in compressive strength[2] replacing of $10 \%$ and $30 \% \mathrm{RCA}, 5 \%$ and $10 \% \mathrm{CR}$ and $1 \%$ and $2 \%$ fibre content, As RCA,CR and fibre content increased, workability in terms of slump is reduced[3]different percentages of crumb rubber as a partial replacement of both fine and coarse aggregate by $(0,10,20$, and $30 \%)$ up to $10 \% \mathrm{CR}$ compressive strength is improved.[4]replacing of river sand with manufactured sand of geo polymer concrete $(0$ to $100 \%$ ) increase in compression strength. [5]Use of crump rubber reduce the short term strength properties whereas use of fly ash and high water reducing admixtures improved the long term strengths. [7] Workability of concrete with $10 \%$ crump rubber is reduced slightly when compared with conventional concrete. In this investigation, $20 \%$ of cement is replaced with fly ash and fine aggregate with manufactured sand and crumb rubber.

\section{MATERIALS}

\subsection{Ordinary Portland cement}

In this study, 53 grades ordinary Portland cement is used. The cement used in trail work is fresh and doesn't contain any lumps. Testing of cement is carried out as per IS:12269-1987.

Table1: Properties of cement used for the work

\begin{tabular}{|c|c|}
\hline PROPERTY & TEST RESULT \\
\hline Normal Consistency & $32 \%$ \\
\hline Specific Gravity & 3.15 \\
\hline Initial Setting Time & 56 Minutes \\
\hline Final Setting Time & 270 Minutes \\
\hline $\begin{array}{c}\text { Compressive strength } \\
\text { for 28davs }\end{array}$ & $54 \mathrm{Mpa}$ \\
\hline
\end{tabular}

\subsection{Fly ash}

In this experimental work class F fly ash is used. Which is extracted from the thermal power plant (Vijayawada).Class F fly ash has high alumina, silica and higher Loss of ignition. It is highly pozzolanic in 
nature, reacts with excess lime generated in the hydration of cement.

\subsection{Fine Aggregate}

In this work manufactured sand IS: 383-1970, and crumb rubber is used

\subsection{Crumb rubber}

Waste rubber tyre are made into rubber sheet, sheet are sent to special mills to make them small particles. In a this process, particles generated are with more irregularity in the range of $4.75 \mathrm{~mm}-425$ microns. where average size of $2 \mathrm{~mm}$, which is obtained from the Priyanka rubber industry Hyderabad.

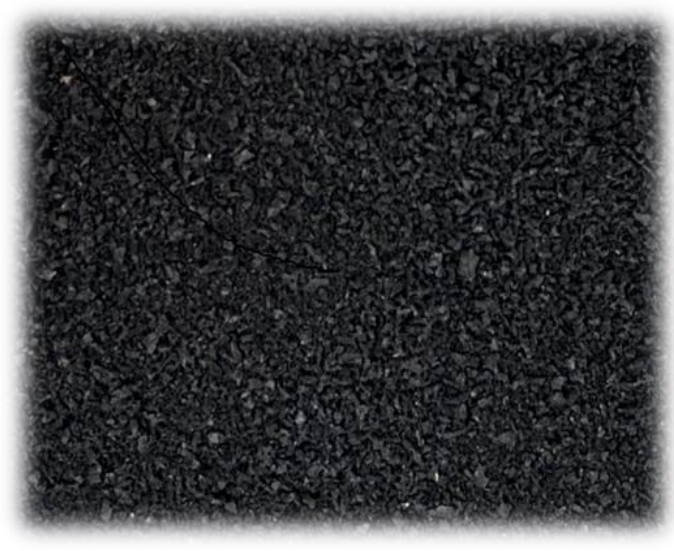

Fig.1 Crumb Rubber

\subsection{Sand or Manufactured sand}

Waste obtained from the crushing plants, particle size less than $4.75 \mathrm{~mm}$ to $150 \mathrm{~mm}$. As it is thrown as waste, can be used as a supplement, collected from the local plants.

\subsection{Coarse aggregate}

$20 \mathrm{~mm}$ crushed angular aggregate used in this experiment study. It is collected from crushing plants, local plants available nearby.

\subsection{Super plasticizer}

To improve workability of concrete, Sulphonated Naphthalene Formaldehyde SNF is used.

\section{EXPERIMENTAL INVESTIGATION 3.1. Mix proportion}

To carry out this experimental work, grade of concrete is M20. The mix proportion for M20 grade is grade is considered as 1:1.73:2.83, cement, fine aggregate and coarse aggregate respectively and 0.5 is water cement ratio. The mix proportion code is IS456-2000, IS102622006.

\subsection{Casting and Demoulding}

Weighing all the materials in the electronic meter. Batching is performed for each combinations. Mixing is done by using mixture for 3-4 minutes. First the cube moulds are clean well and apply oil to the inner surface. Then fill moulds with concrete prepared in three layers and compact each layer with the tamping rod. The concrete is undisturbed for $24 \mathrm{hrs}$ to set the mix's are identified by marking as M1, M2, M3, M4, M5, After 24 hrs. The moulds are demoulded and are cured with water.

\subsection{Workability Test}

The workability test of the concrete is done as per (IS1199-1959) by preparing the required concrete according to the mix, the slump cone is oiled the inner surface of the cone and arranged on the flat surface, then slump cone is filled with concrete in three layers and slowly remove the cone, observed slump as true, shear, collapse slumps.

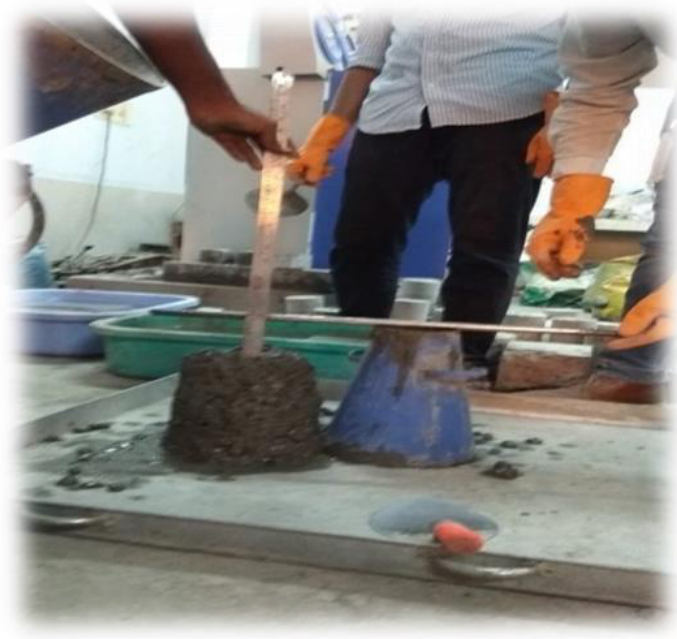

Fig.2 slump cone test for $20 \%$ crumb rubber

\subsection{Compressive Strength of Concrete:}

$100 \mathrm{~mm}$ cube are prepared, to find the compressive strength of M 20 grade of concrete. Three cubes are casted to find strength concrete after 3 days.

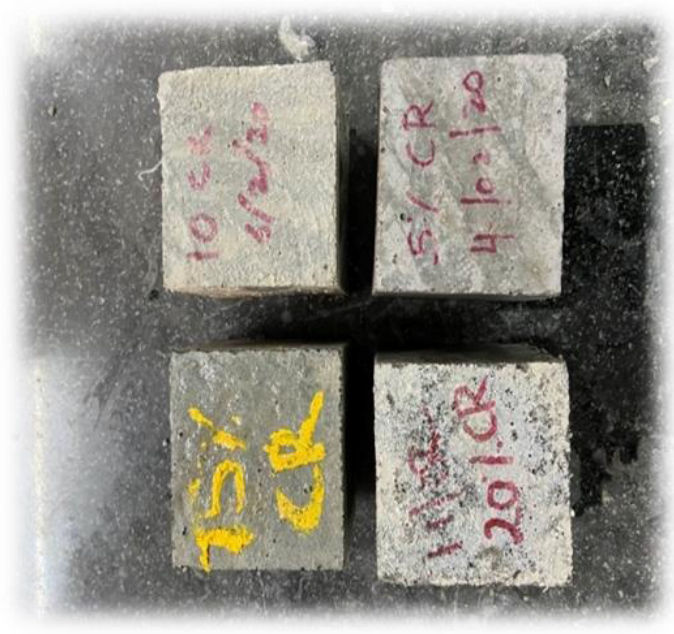

Fig.3 Different cubes with different \% of crumb rubber 


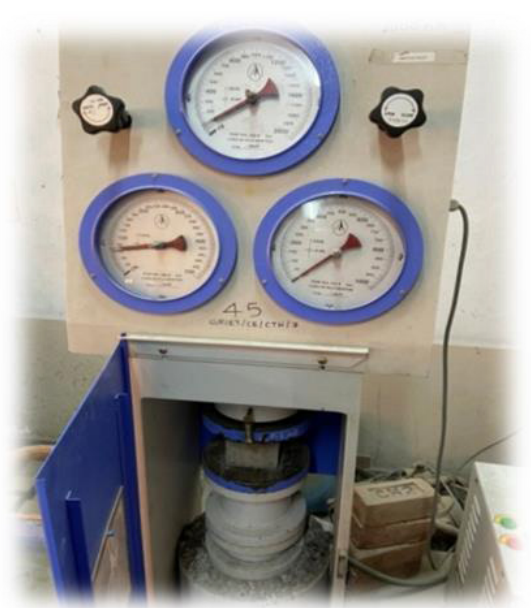

Fig.4 Testing of Compressive strength for $20 \%$ crumb rubber

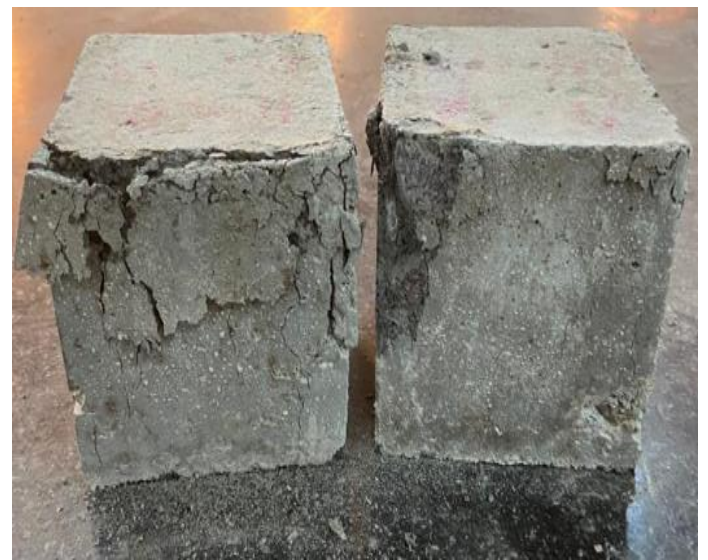

Fig.5 cubes after compressive strength test, $15 \%$ Crumb rubber

\subsection{Mix Proportion of Concrete}

The mix Proportion used for M20 grade concrete with the ratio of $1: 1.73: 2.83$. The mix is designed as per IS10262-2006, IS456-2000.

Table.2 MIX PERCENTAGES

\begin{tabular}{|c|c|c|c|c|}
\hline MIX & $\begin{array}{c}\text { OPC } \\
\text { CEMENT } \\
\text { Percentage }\end{array}$ & $\begin{array}{c}\text { FLYASH } \\
\text { Percentage }\end{array}$ & $\begin{array}{c}\text { MSAND } \\
\text { Percentage }\end{array}$ & $\begin{array}{c}\text { CRUMB } \\
\text { RUBBER } \\
\text { Percentage }\end{array}$ \\
\hline Mix1 & 80 & 20 & 100 & 0 \\
\hline Mix2 & 80 & 20 & 95 & 5 \\
\hline Mix3 & 80 & 20 & 90 & 10 \\
\hline Mix4 & 80 & 20 & 85 & 15 \\
\hline Mix5 & 80 & 20 & 80 & 20 \\
\hline
\end{tabular}

\section{TEST RESULTS}

4.1 Workability test: The workability of M20 fresh concrete for varies mixes is done by slump cone is shown in the table below.

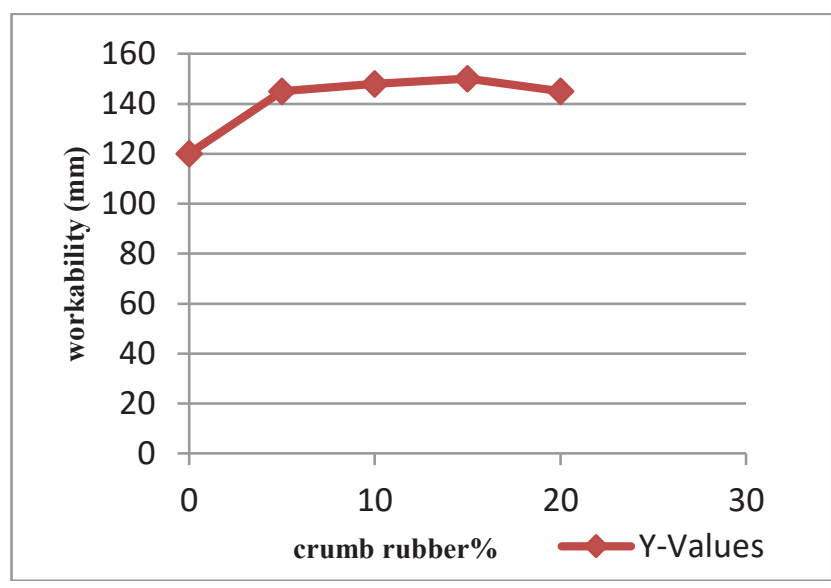

Fig.6 The graph for crumb rubber percentage and workability

\subsection{Compressive strength test}

The compression test is done in this investigation is for 3 days.which is shown in the table

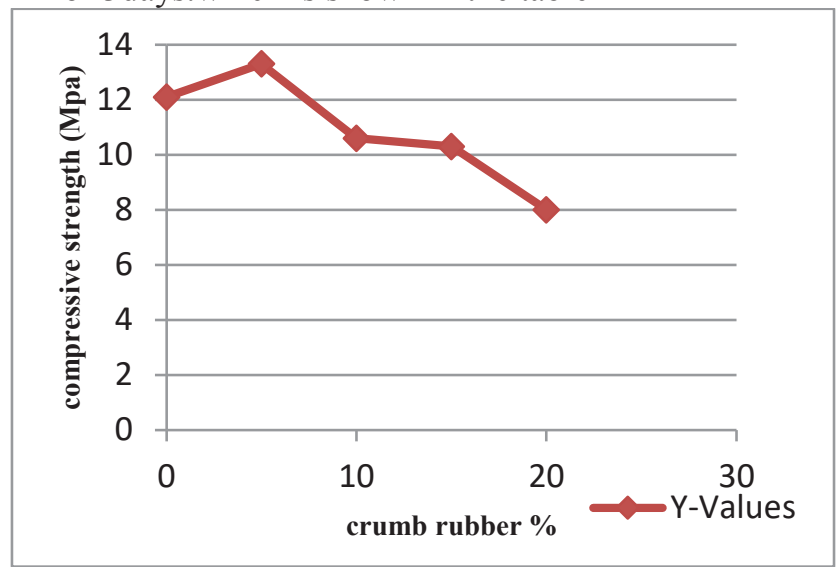

Fig.7 The graph for crumb rubber percentage and compressive strength

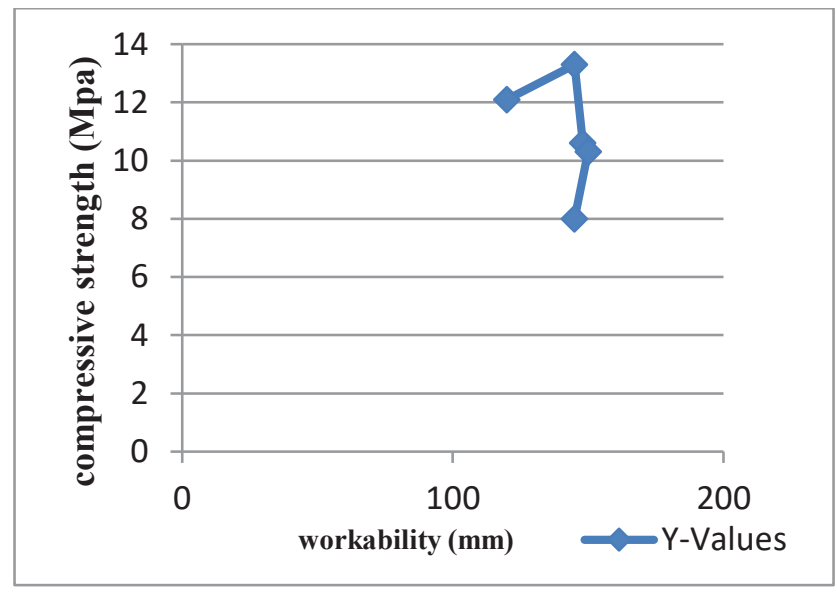

Fig.8 The graph between workability and compressive strength

\section{CONCLUSION}

The conclusions of the experimental investigation are mentioned below:

1. The workability of the concrete(M20) increased up to $15 \%$ replacement of crumb rubber, is slightly reduces for the $20 \%$ replacement of the CR. 
2. The compressive strength of the above mixes increased for 3days strength for M20 grade concrete $45-50 \%$, the compressive strength for this mixes increases up to $15 \%$ then after it is observed a minor down fall in compressive strength.

\section{REFERENCES}

1. EshmaielGanjian ,MortezaKhorami , Ali Akbar Maghsoudi ,"Scrap tyre rubber replacement for aggregate and filler in concrete".ELSEVEIR23(2009)1828-1836.

2. F.M. ZahidHossain, Md. Shahjalal, Kamrul Islam , Mohammad Tiznobaik, M. ShahriaAlam (2019). "Mechanical properties of recycled aggregate concrete containing crumb rubber and polypropylene fiber”. ELSEVIER-225 (2019) 983996.

3. AlyMuhammedAly, M.S. El-Feky, Mohamed Kohail , El-Sayed A.R. Nasr (2019). "Performance of geopolymer concrete containing recycled rubber". ELSEVIER-207 (2019) 136-144.

4. Dr.T.Srinivas,K. Veerababu, Dr.N.V.RamanaRao. "Experimental investigation on mechanical properties of geopolymer concrete when river sand replaced with manufactured sand as fine aggregate". IJRAT Special issue ICADMMES 2018,E-ISSN:2321-9637.

5. Tummala Suresh Kumar, Kosaraju Satyanarayana, Materials Today: Proceeding, 26 (2), 3228-3233, (2020).

6. A.R. Khaloo, M. Dehestani, P. Rahmatabadi," Mechanical properties of concrete containing a high volume of tire-rubber particles," Waste Manage. 28 (2008) 2472-2482.

7. Siddique R, Naik TR. "Properties of concrete containing scrap-tire rubber - an overview." Waste Manage 2004;24(1):563-9

8. O. Youssf, R. Hassanli, J.E. Mills," Mechanical performance of FRP-confined and unconfined crumb rubber concrete containing high rubber content," J. Build. Eng. 11 (2017) 115-126

9. M.A. Aiello, F. Leuzzi, "Waste tyre rubberized concrete: properties at fresh and hardened state", Waste Manage. 30 (2010) 1696-1704. 